\title{
Ulcerative Colitis and Grave's Disease: Is There Any Relationship?
}

\author{
Salwa Baki ${ }^{\mathrm{a}, \mathrm{c}}$, Safaa Gharaba ${ }^{\mathrm{b}}$, Ghizlane El Mgharia ${ }^{\mathrm{a}}$ Zhour Semlani $^{\mathrm{b}}$, Sofia Oubaha ${ }^{\mathrm{b}}$, \\ Khadija Krati ${ }^{b}$, Nawal El Ansari ${ }^{\mathrm{a}}$
}

\begin{abstract}
The association between Grave's disease and inflammatory bowel disease is well known in the medical literature. However, it is uncertain whether this link is due to a specific cause or just a simple coincidence. In most cases, the diagnosis of thyroid disease has preceded that of ulcerative colitis (UC). In this paper, we studied the case of a female patient developing Grave's disease years after being diagnosed with UC, and we reviewed the literature exploring a possible autoimmune relationship.
\end{abstract}

Keywords: Grave's disease (GD); Ulcerative colitis (UC); Inflammatory bowel disease (IBD); Thyroid

\section{Introduction}

Ulcerative colitis (UC) is a form of inflammatory bowel disease (IBD) that is characterized by a chronic inflammation of the large bowel, which starts from rectal mucosa and spreads to its proximal parts. It results from defects in the barrier function of the intestinal epithelium and in inappropriate activation of the immune mucosal system [1]. Extra-intestinal manifestations have been described as associated with UC including ankylosing spondylitis, arthritis, pyoderma gangrenosum, etc. [2]. The connection between autoimmune thyroiditis and IBD is well known in the literature, but thyroid disorders have not been considered extra-intestinal manifestations of UC. In most cases, the diagnosis of thyroid disease has preceded that of IBD. Early studies have suggested a relationship between thyroid abnormalities and UC [3]. But it is still uncertain whether the coexistence of Grave's and UC diseases is due to a specific reason or a coincidence.

Manuscript accepted for publication January 21, 2016

aEndocrinology, Diabetes and Metabolism Department, University Hospital Mohamed VI, PCIM Laboratory, Faculty of Medicine, Marrakesh, Morocco

${ }^{\mathrm{b}}$ Gastroenterology Department, University Hospital Mohamed VI, Marrakesh, Morocco

${ }^{\mathrm{c} C o r r e s p o n d i n g ~ A u t h o r: ~ S a l w a ~ B a k i, ~ E n d o c r i n o l o g y, ~ D i a b e t e s ~ a n d ~ M e t a b o-~}$ lism Department, University Hospital Mohamed VI, PCIM Laboratory, Faculty of Medicine, Marrakesh, Morocco. Email: salwabaki@gmail.com

doi: http://dx.doi.org/10.14740/jem330w
We will report the case of a lady developing Grave's disease (GD) years after being diagnosed with UC disease, and we will review the literature exploring a possible autoimmune relationship.

\section{Case Report}

A 34-year-old female, non-smoker, with an 8-year history of UC was examined at the outpatient clinic of the university hospital for a regular follow-up of her IBD. The patient underwent a hemicolectomy 2 years earlier and has been under salazopyrin and corticoids since then. During the ensuing years, the patient experienced both remission and exacerbation of the disease. The anamnesis was unremarkable. Her height and weight were $158 \mathrm{~cm}$ and $51 \mathrm{~kg}$, respectively. The patient complained of weight loss over the past 9 months. Her initial weight was $61 \mathrm{~kg}$. On physical examination, her blood pressure was measured at 110/90 $\mathrm{mm} \mathrm{Hg}$, pulse at $110 \mathrm{bpm}$, and temperature at $37{ }^{\circ} \mathrm{C}$. There was a bilateral mild exophthalmos, with no tremor or goiter or any palpable thyroid nodule. The patient described a recent asthenia with aggravation of diarrhea.

\section{Investigation}

Laboratory tests revealed normal blood count and blood chemical evaluation. The results of thyroid function tests were as follows: TSHus $=0.083 \mathrm{mUI} / \mathrm{mL}$ (normal range $0.34-5.6 \mathrm{mUI} /$ $\mathrm{mL}$ ), serum free T3 $=5.2 \mathrm{pg} / \mathrm{mL}$ (normal range $2.50-3.90 \mathrm{pg}$ / $\mathrm{mL}$ ), and serum free T4 $=2.1 \mathrm{ng} / \mathrm{dL}$ (normal range $0.6-1.12$ $\mathrm{ng} / \mathrm{dL}$ ). The diagnosis of hyperthyroidism being made, antithyroperoxidase (anti-TPO), antithyroglobulin (anti-TG) and thyrotropin receptor antibodies (TRAK) were ordered. The results were positive for TRAK. Thyroid ultrasonography revealed an enlarged thyroid, whereas the Tc-99m pertechnetate thyroid scintigraphy revealed a homogenously increased activity in a moderately enlarged thyroid (Fig. 1). The electrocardiogram showed a sinus tachycardia with a rate of about 100 beats/min.

\section{Treatment}

Treatment with carbimazole and propranolol was initiated. The patient is now at her 12th month of carbimazole treatment 


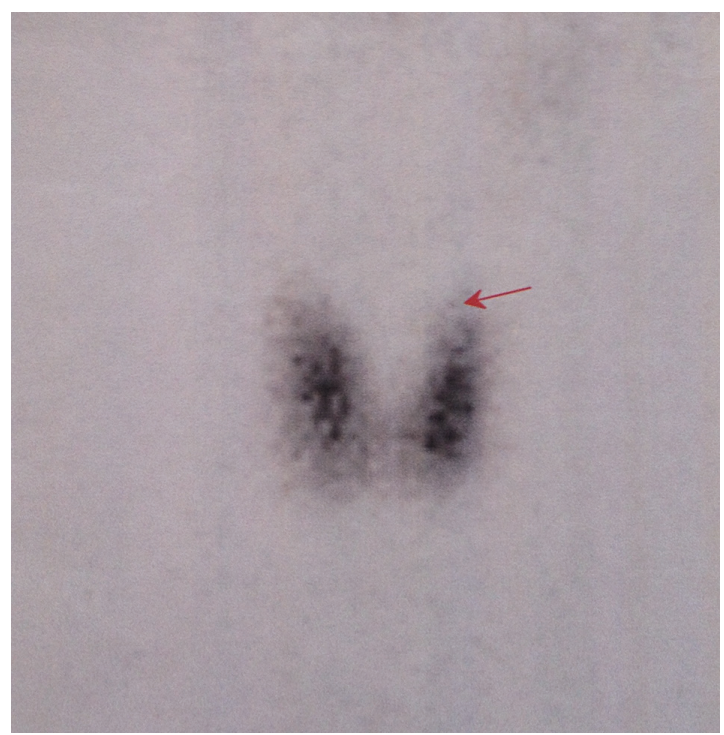

Figure 1. Tc-99m pertechnetate thyroid scintigraphy showing a homogenously increased activity in a moderately enlarged thyroid.

at $20 \mathrm{mg} /$ day.

\section{Outcome and follow-up}

The thyroid function test, which was done after 6 weeks of carbimazole treatment, revealed a suppressed TSHus of $0.1 \mathrm{mUI} /$ $\mathrm{mL}$, normal free $\mathrm{T} 4$ concentration of $1.05 \mathrm{ng} / \mathrm{dL}$ and normal free $\mathrm{T} 3$ of $3.15 \mathrm{pg} / \mathrm{mL}$. The actual thyroid function test was normal with a TSHus of $3.2 \mathrm{mUI} / \mathrm{mL}$. Under medical treatment, the patient experienced a reduction in diarrhea occurrence.

\section{Discussion}

The association between UC and thyroid disease was first de- scribed in 1968 [4]. Since then, several reports were published describing single cases or studies on small groups of patients. The UC is considered a systemic disease with extra-intestinal manifestations that often involve several organs. The prevalence reported varies from $6 \%$ to $47 \%$. Table 1 reports these extra-intestinal manifestations of IBD in general and UC in particular [1].

The incidence of thyrotoxicosis ranged from $0.82 \%$ to $3.7 \%$ [3]. An increased prevalence of thyroid disorders (two to four times higher than that of the general population) has been reported in UC patients [4]. However, a recent study exploring the prevalence of hyper/hypothyroidism seen in patients with UC found a low prevalence in UC patients when compared to a control group [5]. The interval between the occurrence of the two diseases ranged from simultaneous to many years [6]. The features of the cases of UC association with autoimmune thyroid diseases reported in the literature are summarized in Table 2 [3, 4, 6-18]. In most cases, thyroid diseases have preceded the diagnosis of UC while in our case the UC was diagnosed first.

To date, thyroid disorders are not classified as extra-intestinal manifestation of UC [2]. Despite the possibility of fortuitous association, a possible link between the two pathological conditions has been previously suggested [19].

Immune response has been shown to be polyclonal in both autoimmune thyroiditis and IBD [20]. GD and UC were initially considered a Th2 type disease $[19,20]$. This Th2 driven pathway has been considered one of the causes of the lower prevalence of autoimmune thyroid disease in Crohn's disease as compared with UC. However, recent reports have suggested the intervention of other cells in the UC pathogenesis such as the innate lymphoid cell groups 3 (ILC3) and the Th17 cells [21]. The Th1 dominance has been also described as a predominant pathway in the initial and active phases of the GD [22, 23]. Another possible autoimmune link is $\mathrm{C}-\mathrm{X}-\mathrm{C}$ motif ligand (CXCL) 10 which appears to contribute to the pathogenesis of many autoimmune diseases. CXCL 10 is secreted by several cell types such as endothelial cells, fibroblasts, keratinocytes, preadipocytes, etc. However, further investigation is needed

Table 1. Extra-Intestinal Manifestations of IBD

\begin{tabular}{ll}
\hline Extra-intestinal manifestation & Diseases \\
\hline Musculoskeletal system & Peripheral arthritis, ankylosing spondylitis, isolated sacroiliitis \\
Mucocutaneous system & Erythema nodosum, pyoderma gangrenosum, aphthous stomatitis/oral ulceration \\
Eye & Anterior uveitis, conjunctivitis, iritis, scleritis/episcleritis \\
Hepatobiliary system & Primary sclerosing cholangitis \\
Pancreas & Acute pancreatitis, chronic pancreatitis, exocrine insufficiency \\
Vascular system & Thromboembolic events \\
Kidney & Tubular proteinuria \\
Bronchopulmonary system & Chronic bronchitis/bronchiolitis/bronchiectasis, acute laryngotracheitis/tracheal \\
& stenosis - bronchiolitis obliterans organizing pneumonia, pleuritis/serositis \\
Heart & Pericarditis, myocarditis \\
Neurological system & Demyelinating diseases including multiple sclerosis, optic neuritis, sensorial \\
& hearing loss \\
\hline
\end{tabular}


Table 2. Reported Cases of UC and Autoimmune Thyroiditis Association

\begin{tabular}{|c|c|c|c|c|c|}
\hline Authors & Age & Sex & $\begin{array}{l}\text { Nature of autoimmune } \\
\text { thyroid disease }\end{array}$ & Order of occurrence & $\begin{array}{l}\text { Other associated } \\
\text { autoimmune disease }\end{array}$ \\
\hline Powell et al [4] & 34 & Female & Grave's disease & Simultaneous & Addison's disease \\
\hline Jarnerot et al [3] & 73 & Female & Grave's disease & Simultaneous & - \\
\hline Triantafillidis et al [7] & 42 & Male & Grave's disease & Simultaneous & - \\
\hline Eugene et al [6] & 41 & Female & Grave's disease & Simultaneous & - \\
\hline \multirow[t]{2}{*}{ Modebe [8] } & 41 & Female & Grave's disease & Grave's disease first & - \\
\hline & 32 & Female & Grave's disease & Grave's disease first & - \\
\hline Baldys-Waligorska et al [9] & 45 & Female & Hashimoto thyroiditis & Hashimoto thyroiditis first & Arthritis \\
\hline Topal et al [10] & 46 & Female & Hashimoto thyroiditis & Hashimoto thyroiditis first & Vitiligo \\
\hline Nishimura et al [11] & 26 & Female & Grave's disease & Ulcerative colitis first & - \\
\hline Oshitani et al [12] & 61 & Female & Grave's disease & Ulcerative colitis first & $\begin{array}{l}\text { Dermatomyositis, } \\
\text { multiple mononeuritis }\end{array}$ \\
\hline Ito et al [13] & 46 & Male & Grave's disease & Grave's disease first & - \\
\hline Chiba et al [14] & 66 & Female & Grave's disease & Ulcerative colitis first & - \\
\hline Hasegawa et al [15] & 41 & Female & Grave's disease & Simultaneous & - \\
\hline Nakamura et al [11] & 50 & Male & Grave's disease & Grave's disease first & - \\
\hline Okai et al [16] & 30 & Female & Grave's disease & Grave's disease first & - \\
\hline \multirow[t]{2}{*}{ Lyer et al [17] } & 46 & Female & Grave's disease & Grave's disease first & - \\
\hline & 18 & Male & Grave's disease & Grave's disease first & - \\
\hline Najafi et al [18] & 20 & Male & Hashimoto thyroiditis & Simultaneous & $\begin{array}{l}\text { Type } 1 \text { diabetes, } \\
\text { autoimmune hepatitis }\end{array}$ \\
\hline
\end{tabular}

to prove the specific role of CXCL in both diseases [22]. An extra possible factor to be considered is the higher prevalence of iodine deficiency in patients with IBD especially in our geographical area [2]. The genetic factor has also been considered. A number of overlapping regions of linkage have been demonstrated from genome-wide linkage and association studies in these two diseases [24]. Recent studies have also revealed that some genes including PTPN22 and CTLA4 are associated with the occurrence of UC. These genes are considered risk factors for human autoimmunity $[25,26]$.

The association of UC and GD can trigger therapeutic issues. It is suggested that hyperthyroidism in the active stage may cause deterioration of UC and vice versa [25]. Also, the rapid metabolism of the drugs required to treat $\mathrm{UC}$ or the rapid transit of the antithyroid drugs through the gut may prevent them from attaining effective concentrations.

The treatment of UC depends on the severity of the disease. The initial course of action involves corticosteroids and anti-inflammatory agents (e.g., sulfasalazine, infliximab, golimumab, etc.). Symptomatic treatment is also prescribed (antidiarrheic agents and rehydration). Surgery is only considered when medical treatment fails or in case of a surgical emergency such as colon perforation. Once remission has been achieved, maintenance therapy is recommended for all patients to prevent relapse [1]. The treatment of GD consists of anti-thyroid drugs combined with symptomatic treatment.

The relationships between IBD and thyroid disorders are not fully established. However, a thyroid function test may be required in patients with $\mathrm{UC}$, especially for those with long standing and severe disease or for patients who present clinical signs of thyroid dysfunction. The test is also performed when there is no response to standard therapeutics such as silent hyperthyroidism that has been reported [24].

\section{Conclusion}

Diarrhea is the main symptom of both GD and UC. A thyroid function test may be required for patients with UC, especially for those who are refractory to a conventional therapy. Physicians should take into consideration an IBD in a patient with GD especially when diarrhea persists despite the favorable course of GD.

\section{Conflicts of Interest}

The authors declare that there is no conflict of interest that could affect the impartiality of this research.

\section{Funding}

This research did not receive any grant from any public, com- 
mercial, or non-profit organizations.

\section{Author Contributions}

SB and SG were responsible for the case note review and literature research and wrote the case report. GEM, SO and ZS examined the patient in the ward and in the outpatient clinic while KK and NEA were responsible for the manuscript revision.

\section{References}

1. Stenson W. Inflammatory Bowel Disease. In: Goldman L, Ausiello D, Arend W. Cecil Medicine. 23rd ed. Philadelphia: Saunders Elsevier Publications. 2008; p. 10421049.

2. Rothfuss KS, Stange EF, Herrlinger KR. Extraintestinal manifestations and complications in inflammatory bowel diseases. World J Gastroenterol. 2006;12(30):4819-4831.

3. Jarnerot G, Azad Khan AK, Truelove SC. The thyroid in ulverative colitis and Crohn's disease. II. Thyroid enlargement and hyperthyroidism in ulcerative colitis. Acta Med Scand. 1975;197(1-2):83-87.

4. Powell JR, Shapiro HA, Carbone JV. Therapeutic problems of ulcerative colitis with hyperthyroidism. Am J Gastroenterol. 1968;50(2):116-124.

5. Casella G, De Marco E, Antonelli E, Daperno M, Baldini V, Signorini S, Sannella F, et al. The prevalence of hyperand hypothyroidism in patients with ulcerative colitis. J Crohns Colitis. 2008;2(4):327-330.

6. Bonapace ES, Srinivasan R. Simultaneous occurrence of inflammatory bowel disease and thyroid disease. Am J Gastroenterol. 2001;96(6):1925-1926.

7. Triantafillidis JK, Manoussakis CA, Tsafaras C, Koutsorizof A. Coexistence of thyreotoxicosis and exacerbation of ulcerative colitis. Am J Gastroenterol. 1990;85(7):908-910.

8. Modebe O. Autoimmune thyroid disease with ulcerative colitis. Postgrad Med J. 1986;62(728):475-476.

9. Baldys-Waligorska A, Kusnierz-Cabala B, Huszno B. [A special case of thyroid associated ophthalmopathy in the course of Graves-Basedow disease]. Endokrynol Pol. 2006;57(5):536-540.

10. Topal F, Senel E, Akbulut S, Dolek Y. A new combination of multiple autoimmune syndrome? Coexistence of vitiligo, autoimmune thyroid disease and ulcerative colitis. Dermatol Reports. 2011;3(2):e19.

11. Nishimura M, Yamamoto T, Iijima H, Moriwaki Y, Takahashi S, Hada T. Basedow's disease and chronic ulcerative colitis: a case report and review of the Japanese literature. Intern Med. 2001;40(1):44-47.

12. Oshitani H, Wakabayashi Y, Sawaguchi Y, Koike H, Yoshino Y. A case of dermatomyositis followed by multiple mononeuritis, with the history of ulcerative colitis and Basedow's disease. J Kyorin MedSoc. 12:47-53.

13. Ito M, Funauchi M, Fukuma N, et al. A case of hyperthyroidism complicated with ulcerative colitis. Saishin
Igaku. 39:167-171.

14. Chiba M, Naganuma T, Goto M, et al. A case of ulcerative colitis complicated by antibiotic-induced pseudomembranous colitis with reference to association of Basedow's disease. Gastroenterol Endosc. 27:2797-2805.

15. Hasegawa H, Hasegawa K, Saito T, Kowa H, Nonaka I. [A case of myopathy with ulcerative colitis]. Rinsho Shinkeigaku. 1990;30(2):184-188.

16. Okai K, Machida K, Nishi M, Nanjo K. [Complications of extraintestinal endocrine disease associated with ulcerative colitis - association of ulcerative colitis and autoimmune thyroid disease]. Nihon Rinsho. 1999;57(11):25362539.

17. Iyer SK, Karlstadt RG. Hyperthyroidism and ulcerative colitis: report of two cases and a review of the literature. J Natl Med Assoc. 1980;72(2):127-131.

18. Najafi M, Zamani MM, Rezaei N, Sabbaghian M. Autoimmunity in inflammatory bowel disease: a case of ulcerative colitis with diabetes mellitus, autoimmune hepatitis and autoimmune hypothyroidism. Turk J Pediatr. 2012;54(6):651-653.

19. Geng X, Biancone L, Dai HH, Lin JJ, Yoshizaki N, Dasgupta A, Pallone F, et al. Tropomyosin isoforms in intestinal mucosa: production of autoantibodies to tropomyosin isoforms in ulcerative colitis. Gastroenterology. 1998;114(5):912-922.

20. Inokuchi T, Moriwaki Y, Takahashi S, Tsutsumi Z, Ka T, Yamamoto T. Autoimmune thyroid disease (Graves' disease and hashimoto's thyroiditis) in two patients with Crohn's disease: case reports and literature review. Intern Med. 2005;44(4):303-306.

21. Wallace KL, Zheng LB, Kanazawa Y, Shih DQ. Immunopathology of inflammatory bowel disease. World J Gastroenterol. 2014;20(1):6-21.

22. Antonelli A, Ferrari SM, Giuggioli D, Ferrannini E, Ferri C, Fallahi P. Chemokine (C-X-C motif) ligand (CXCL)10 in autoimmune diseases. Autoimmun Rev. 2014;13(3):272-280.

23. Niessner M, Volk BA. Altered Th1/Th2 cytokine profiles in the intestinal mucosa of patients with inflammatory bowel disease as assessed by quantitative reversed transcribed polymerase chain reaction (RT-PCR). Clin Exp Immunol. 1995;101(3):428-435.

24. Bueno de Mesquita M, Ferrante M, Henckaerts L, Joossens M, Janssens V, Hlavaty T, Pierik M, et al. Clustering of (auto)immune diseases with early-onset and complicated inflammatory bowel disease. Eur J Pediatr. 2009;168(5):575-583.

25. Diaz-Gallo LM, Espino-Paisan L, Fransen K, GomezGarcia M, van Sommeren S, Cardena C, Rodrigo L, et al. Differential association of two PTPN22 coding variants with Crohn's disease and ulcerative colitis. Inflamm Bowel Dis. 2011;17(11):2287-2294.

26. Chen Z, Brant SR, Li C, Shrestha UK, Jiang T, Zhou F, Jiang Y, et al. CTLA4 -1661A/G and 3'UTR long repeat polymorphisms are associated with ulcerative colitis and influence CTLA4 mRNA and protein expression. Genes Immun. 2010;11(7):573-583. 